\title{
Climbing fiber signaling and cerebellar gain control
}

\author{
Gen Ohtsuki ${ }^{1,2}$, Claire Piochon $^{1}$ and Christian Hansel ${ }^{1,2 *}$ \\ Department of Neurobiology, University of Chicago, Chicago, IL, USA \\ 2 Department of Neuroscience, Erasmus University Medical Center, Rotterdam, The Netherlands
}

\section{Edited by:}

Egidio D'Angelo, University of Pavia,

Italy

\section{Reviewed by:}

Masao Ito, RIKEN, Japan

David Linden, Johns Hopkins

University, USA

\section{${ }^{*}$ Correspondence:}

Christian Hansel, The University of Chicago, Department of Neurobiology, 947 E. 58th Street/J243, Chicago,

IL 60637, USA.

e-mail: chansel@bsd.uchicago.edu
The physiology of climbing fiber signals in cerebellar Purkinje cells has been studied since the early days of electrophysiology. Both the climbing fiber-evoked complex spike and the role of climbing fiber activity in the induction of long-term depression (LTD) at parallel fiber-Purkinje cell synapses have become hallmark features of cerebellar physiology. However, the key role of climbing fiber signaling in cerebellar motor learning has been challenged by recent reports of forms of synaptic and non-synaptic plasticity in the cerebellar cortex that do not involve climbing fiber activity, but might well play a role in cerebellar learning. Moreover, cerebellar LTD does not seem to strictly require climbing fiber activity. These observations make it necessary to re-evaluate the role of climbing fiber signaling in cerebellar function. Here, we argue that climbing fiber signaling is about adjusting relative probabilities for the induction of LTD and longterm potentiation (LTP) at parallel fiber synapses. Complex spike-associated, dendritic calcium transients control postsynaptic LTD and LTP induction. High calcium transients, provided by complex spike activity, do not only favor postsynaptic LTD induction, but simultaneously trigger retrograde cannabinoid signaling, which blocks the induction of presynaptic LTP. Plasticity of the climbing fiber input itself provides additional means to fine-tune complex spike associated calcium signaling and thus to adjust the gain of heterosynaptic climbing fiber control. In addition to dendritic calcium transients, climbing fiber activity leads to the release of the neuropeptide corticotropin-releasing factor (CRF), which facilitates LTD induction at both parallel fiber and climbing fiber synapses.

Keywords: calcium, cerebellum, climbing fiber, corticotropin releasing factor, long-term depression, long-term potentiation, parallel fiber, Purkinje cell

\section{INTRODUCTION}

The first detailed characterization of excitatory synaptic responses to climbing fiber stimulation resulted from intracellular Purkinje cell recordings performed in anaesthetized cats by Eccles, Llinas and Sasaki, working at the time at the Australian National University in Canberra (Eccles et al., 1964, 1966). Stimulation of the climbing fiber input, or the contralateral inferior olive (from which climbing fibers originate) led to an all-or-none 'giant' or 'complex' spike, composed of an initial fast action potential, followed by smaller spikelets superimposed on a sustained depolarization (Eccles et al., 1966). In the mature cerebellum, this massive, excitatory response pattern results from the activity of only one climbing fiber input (Ramón y Cajal, 1911) that remains after a period of developmental elimination of surplus climbing fibers, which in rats occurs during the first 3 weeks of postnatal life (Crépel et al., 1976).

The characteristic complex spike provides a hallmark feature of cerebellar physiology, particularly because of its seemingly invariant nature (for review, see Schmolesky et al., 2002). Another hallmark feature is the role assigned to climbing fiber activity in cerebellar motor learning. It is widely assumed that long-term depression (LTD) at parallel fiber-Purkinje cell synapses, a type of synaptic plasticity that requires co-activation of the parallel fiber and the climbing fiber input, provides the cellular correlate of forms of motor learning. Climbing fiber activity results in large, widespread calcium transients in Purkinje cell dendrites (Miyakawa et al., 1992;
Ross and Werman, 1987), which are required for the induction of cerebellar LTD (Konnerth et al., 1992).

More recent observations suggest that the role of climbing fiber signaling is more complex than that of an invariant 'teacher' signal contributing to LTD induction and, therefore, to cerebellar motor learning. Here, we will discuss recent evidence showing that climbing fiber synapses onto cerebellar Purkinje cells show forms of plasticity as well. Moreover, we will review recent observations on types of synaptic and non-synaptic cerebellar plasticity that do not depend on climbing fiber signaling, suggesting that motor learning is not exclusively linked to climbing fiber activity. Rather, a picture emerges, in which the presence or absence of climbing fiber activity influences induction probabilities for various types of plasticity, thus orchestrating Purkinje cell output patterns and cerebellar gain control.

\section{THE COMPLEX SPIKE: SIGNATURE OF CLIMBING FIBER ACTIVITY}

Climbing fiber synaptic transmission onto Purkinje cells is very powerful and reliable, resulting from the large number of synaptic contact sites formed by an individual climbing fiber input (Palay and Chan-Palay, 1974) as well as from the high probability of release at each climbing fiber terminal (Dittman and Regehr, 1998; Hashimoto and Kano, 1998; Silver et al., 1998). Climbing fiber synapses contact spines on the primary Purkinje cell dendrite, 
whereas parallel fiber synapses contact spines on secondary and tertiary dendritic branches (Strata and Rossi, 1998). Whereas parallel fiber stimulation causes a graded excitatory postsynaptic potential (EPSP) in Purkinje cells, climbing fiber activity is monitored in somatic recordings as an all-or-none complex spike (Eccles et al., 1964, 1966), characterized by a fast sodium spike that is followed by typically two to three spikelets riding on top of a depolarization plateau (Figure 1). Purkinje cell complex spikes occur at low frequencies around $1 \mathrm{~Hz}$, but can reach frequencies up to $11 \mathrm{~Hz}$ when nociceptive stimulation is applied (Ekerot et al., 1987). Each complex spike can be associated with high-frequency firing of spikes in the climbing fiber itself, which can reach frequencies up to $500 \mathrm{~Hz}$ (Maruta et al., 2007). In Purkinje cell dendrites, climbing fiber activation evokes calcium spikes, which have been characterized in early intradendritic recordings (Llinas and Sugimori, 1980). For a long time, however, the origin of the different somatically recorded complex spike components remained unclear (as discussed in Schmolesky et al., 2002). Recent somato-dendritic double-patch recordings demonstrate that dendritically recorded calcium spikes show no obvious relation to the number and occurrence of spikelets within the simultaneously recorded complex spike (Davie et al., 2008). These observations suggest that the typical, somatically recorded complex spike waveform is locally generated, whereas in the dendrite, climbing fiber activity evokes isolated calcium spikes. Simultaneous somatic and dendritic patch-clamp recordings from our lab are shown in Figure 1. In the soma, climbing fiber stimulation evokes complex spikes (black traces). In contrast, the dendritic recordings (blue traces) obtained at distances of about $75 \mu \mathrm{m}$ (Figure 1A) and $100 \mu \mathrm{m}$ (Figure 1B) from the soma, respectively, reveal local climbing fiber responses, which do not show
A Dendrite $(75 \mu \mathrm{m})$
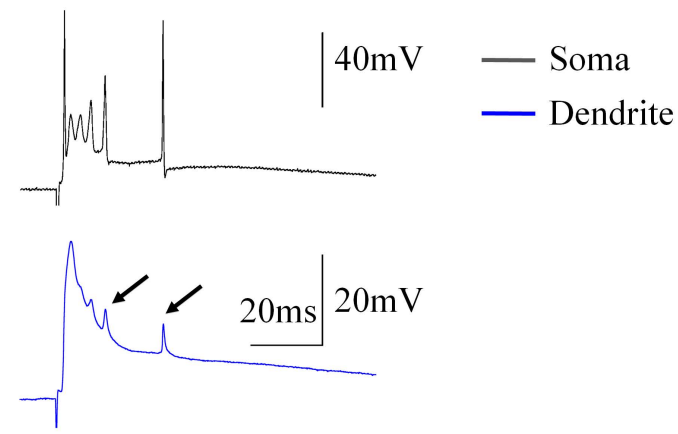

C Proximal dendrite $(10 \mu \mathrm{m})$

$\overline{20 \mathrm{~ms}}$

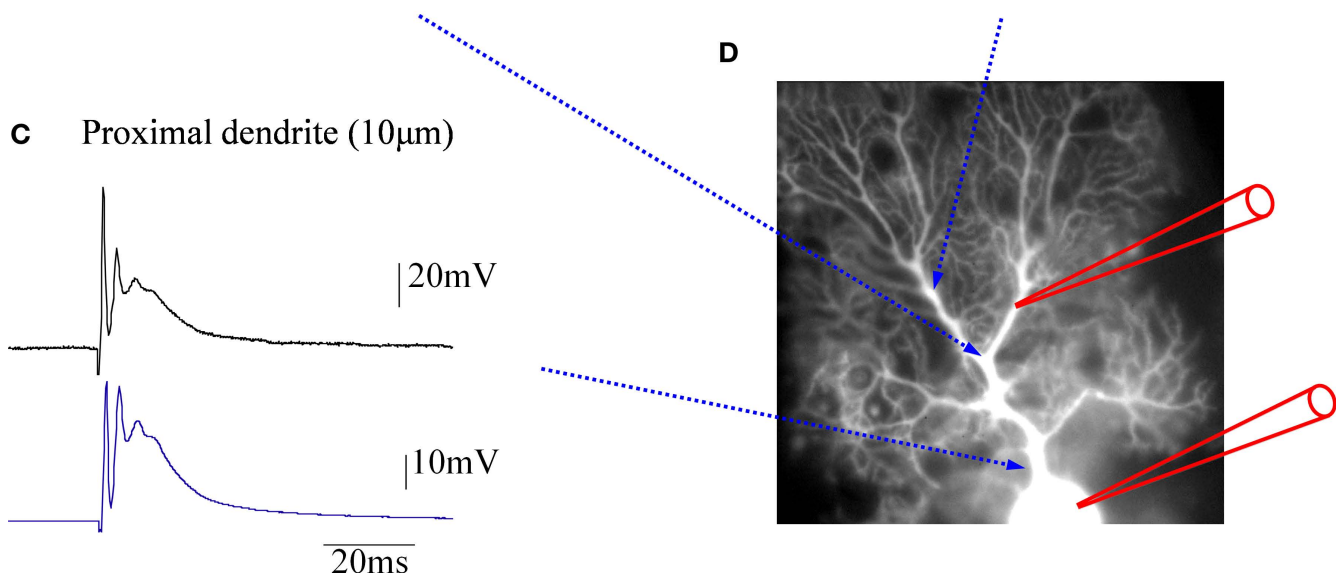

B Distal dendrite $(100 \mu \mathrm{m})$
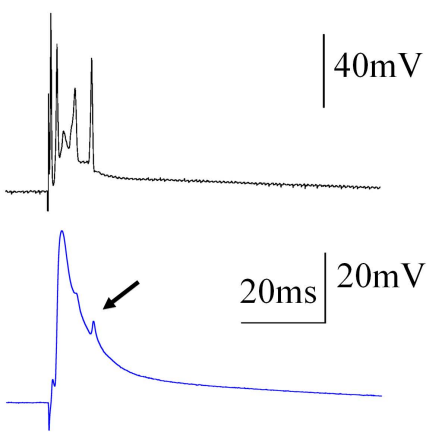

FIGURE 1 | Climbing fiber responses monitored by simultaneous double patch-clamp recordings from the soma and dendrites of cerebellar Purkinje cells. (A) Paired recordings from the soma (black trace) and the dendrite (blue trace). The dendritic patch electrode was located at about $75 \mu \mathrm{m}$ distance from the soma. (B) In this recording, which was obtained from a different Purkinje cell, a more distal location (ca. $100 \mu \mathrm{m}$ ) was selected for the dendritic patch electrode. Small arrows in (A) and (B) point towards small, delayed spikelets seen in the dendritic recordings, that likely reflect sodium action potentials generated in the axon (see corresponding, but larger spikes in the somatic recordings), which passively spread into the dendrite. (C) At a far more proximal location $(\mathrm{ca} .10 \mu \mathrm{m})$, the dendritic recording resembles the complex spike recorded in the soma, but already at this distance an attenuation of the initial, fast sodium spike can be seen. (D) Recording configuration of the experiments
This picture was assembled for illustration purposes only. The recordings were obtained from cerebellar slices prepared from P28-35 Sprague-Dawley rats. Slices were perfused with standard ACSF (as described in Coesmans et al., 2004) bubbled with $95 \% \mathrm{O}_{2}$ and $5 \% \mathrm{CO}_{2}$. The recordings were performed at near-physiological temperature $\left(31-34^{\circ} \mathrm{C}\right)$ using an EPC-10 amplifier (HEKA Electronics, Germany). Currents were filtered at $3 \mathrm{kHz}$, digitized at $10 \mathrm{kHz}$, and acquired using Fitmaster software. The recording electrodes were filled with a solution containing (in mM): $9 \mathrm{KCl}, 10 \mathrm{KOH}, 120 \mathrm{~K}$ gluconate, $3.48 \mathrm{MgCl}_{2}, 10$ HEPES, $4 \mathrm{NaCl}, 4 \mathrm{Na}_{2}$ ATP, $0.4 \mathrm{Na}_{3} \mathrm{GTP}$, and 17.5 sucrose (pH 7.25). Patch electrodes used for somatic recordings had electrode resistances of 3-4 M $\Omega$, and patch electrodes used for dendritic recordings had electrode resistances of 7-10 $\mathrm{M} \Omega$. For climbing fiber stimulation, glass pipettes were used that were filled with ACSF. 
the spikelets that are characteristic for the somatically recorded complex spike. An exception to this are small spikelets that occasionally occur during the late stages of the dendritic climbing fiber response (Figures 1A,B: arrows). These spikelets coincide with late, higher amplitude spikes seen in the somatic recordings. In Purkinje cells, sodium action potentials are initiated in the axon, and passively spread into the dendrite, where their amplitude decreases with increasing distance from the soma (Stuart and Häusser, 1994). The small spikelets seen in our dendritic recordings likely represent those attenuated sodium spikes.

\section{CLIMBING FIBER ACTIVITY EVOKES DENDRITIC CALCIUM TRANSIENTS}

Climbing fibers form so-called 'en passant' synapses with their target Purkinje cells, whose number and distribution along the axis of the Purkinje cell primary dendrite allow for excitatory action throughout the dendritic tree. The most obvious consequence of this unusually tight synaptic contact formed by a single climbing fiber input is a large, widespread calcium transient that accompanies complex spikes (Miyakawa et al., 1992; Ross and Werman, 1987). Climbing fiber-evoked calcium transients not only can be recorded in the primary dendrites (an example of a calcium transient recorded in a primary dendrite spine is shown in Figure 2), but also in secondary and tertiary branches (Miyakawa et al., 1992; Ross and Werman, 1987). Such 'out-of-territory' calcium signaling has also been described in cerebellar Purkinje cells of mormyrid fish (Han et al., 2007), in which the separation of climbing fiber and parallel fiber input territories is even more pronounced. The dendritic tree of these cells is palisade-shaped, with a horizontal dendrite (contacted by the climbing fiber input), and vertical dendrites (contacted by parallel fibers) that show a much lower degree of branching as compared to their mammalian counterparts. Climbing fiber stimulation results in calcium transients in both the horizontal dendrite and the vertical dendrites (Han
A
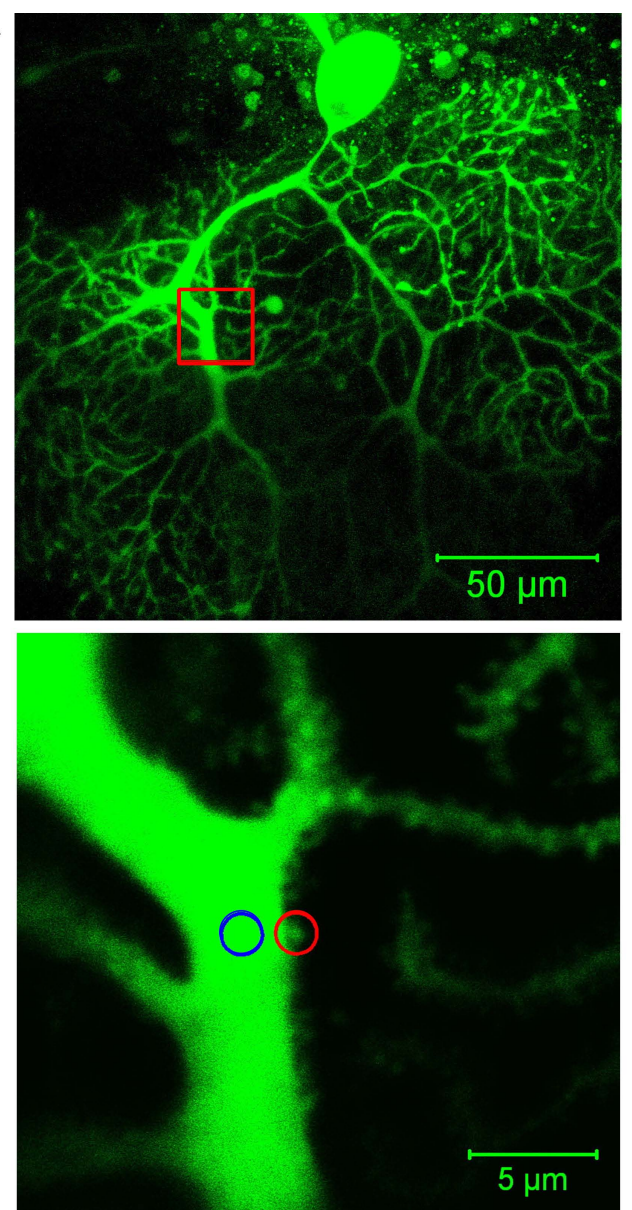

B

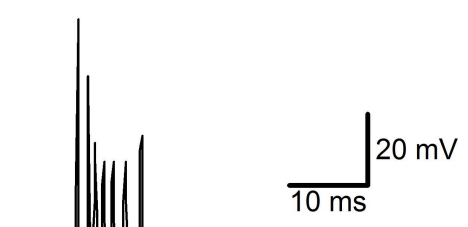

W
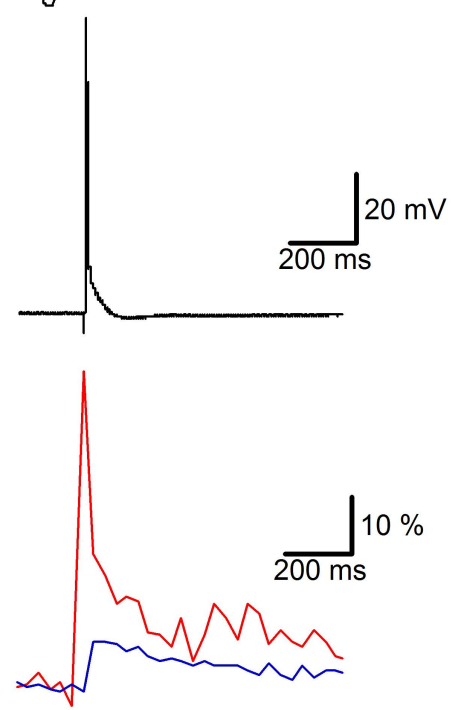

FIGURE 2 | Calcium signaling in a dendritic spine evoked by climbing fiber activity. (A) Top: A rat Purkinje cell (P36) was filled through the patch pipette with the fluorescent calcium indicator Oregon Green BAPTA-2 (200 $\mu \mathrm{M})$. The red box indicates the magnification area. Calcium transients were recorded in a spine (red circle) and in the shaft (blue circle) of the primary dendrite using a Zeiss LSM 5 Exciter confocal microscope and a $\times 63$ Zeiss Apochromat objective (bottom picture). (B) Climbing fiber stimulation evokes a complex spike shown at two different time scales (top), which is associated with a large calcium transient monitored in the spine (red trace), and a smaller transient in the shaft (blue trace; bottom). The calcium traces represent averages of 10 transients (acquired at $30 \mathrm{~s}$ delays), and are displayed as normalized fluorescence changes ( $\triangle F / F$ ). For image acquisition and analysis we used ZEN software (Carl Zeiss Microlmaging, Thornwood, NY, USA). Patch-clamp recording details are described in Figure $\mathbf{1}$. 
et al., 2007). In both mammalian and mormyrid Purkinje cells, calcium influx associated with dendritic calcium spikes is partially mediated by P/Q-type voltage-dependent calcium channels (Han et al., 2007; Usowicz et al., 1992; Watanabe et al., 1998), suggesting that these channels provide the regenerative component needed for the spatial spread of the calcium signal. In spines contacted by parallel fibers, coincident parallel fiber and climbing fiber activity results in supralinear calcium transients (Wang et al., 2000). These spine calcium signals are largest when the parallel fiber activation precedes climbing fiber activation by $50-200 \mathrm{~ms}$, and depend on calcium release from $\mathrm{IP}_{3}$-sensitive calcium stores when the parallel fiber input is weakly activated (Wang et al., 2000). Stronger parallel fiber stimulation results in the activation of more parallel fibers. In this scenario, supralinear calcium signaling is not restricted to individual spines and is mediated by the activation of voltage-dependent calcium channels (Wang et al., 2000). A similar enhancement in dendritic calcium signaling at parallel fiber input sites has been found in mormyrid Purkinje cells upon parallel fiber and climbing fiber stimulation (Han et al., 2007). These observations show that calcium transients evoked by climbing fiber activity do not only invade the parallel fiber input territory, but that they contribute to a local amplification of calcium transients at parallel fiber input sites, even in spines located on distal branchlets that are contacted by parallel fibers (Wang et al., 2000). This is a remarkable finding, as the climbing fiber input itself only contacts spines on the primary dendrite (Strata and Rossi, 1998). The amplitude of the climbing fiber-evoked calcium transient itself also depends on the state of the membrane potential. Synaptic activity of the climbing fiber or the granule cell input can shift the membrane potential to an 'UP' state, while inhibitory inputs can cause a transition towards a 'DOWN' state (Loewenstein et al., 2005; but see Schonewille et al., 2006). Dendritic climbing fiber-evoked calcium transients are smaller following a 'DOWN' state (Rokni and Yarom, 2009). If these bidirectional state transitions occur in vivo, 'UP' states could provide an optimal time window for enhanced dendritic calcium signaling.

\section{GLUTAMATERGIC TRANSMISSION AT CLIMBING FIBER SYNAPSES: NEW PLAYERS IN SIGHT}

Excitatory postsynaptic currents (EPSCs) at climbing fiber synapses are largely mediated by the activation of AMPA receptors (Konnerth et al., 1990; Llano et al., 1991; Perkel et al., 1990) that contain GluR2 subunits and are therefore not permeable to calcium (Hollmann et al., 1991). In the following, we will focus on two additional types of glutamate receptors, whose contribution to climbing fiber signaling (and potential role in calcium signaling) has only recently been fully appreciated: N-methyl-D-aspartate (NMDA) receptors and metabotropic glutamate receptors.

\section{NMDA RECEPTORS}

At many types of excitatory synapses, NMDA receptors provide a major source of calcium influx and are therefore considered as key players in synaptic plasticity (Bliss and Collingridge, 1993). Purkinje cells, in contrast, were until recently assumed to lack functional NMDA receptors. Both NR1 and NR2 subunits are required to form functional NMDA receptors. In Purkinje cells, NR1 subunits are expressed at all ages, from birth throughout adulthood, as consist- ently shown by numerous morphological studies (Monyer et al., 1992, 1994; Moriyoshi et al., 1991; Petralia et al., 1994). During the first postnatal week in rodents, a juvenile form of the NR2 subunit (the NR2D subtype) has clearly been demonstrated in Purkinje cells (Momiyama et al., 1996). However, during this period the resulting NMDA receptors do not contribute to synaptic transmission at parallel fiber or climbing fiber inputs (Lachamp et al., 2005; Llano et al., 1991). In mature Purkinje cells, in situ hybridization and immunohistochemical studies reached contradicting conclusions regarding the expression of NR2 subunits (Monyer et al., 1994; Watanabe et al., 1994; Yamada et al., 2001; but see Akazawa et al., 1994; Thompson et al., 2000). As no NMDA currents were detected in whole-cell patch-clamp recordings (Farrant and CullCandy, 1991; Konnerth et al., 1990; Llano et al., 1991), the notion became widely accepted that Purkinje cells lack functional NMDA receptors.

Recently, this question has been re-examined in older animals (>8-week-old mice) using more selective pharmacological tools (NBQX instead of CNQX as an AMPA receptor antagonist) and a new generation of antibodies. It now appears in the light of these more recent results (Piochon et al., 2007; Renzi et al., 2007) that mature Purkinje cells express functional NMDA receptors from the end of the third postnatal week on, which contain NR2A and/or NR2B subunits. These NMDA receptors are activated by climbing fiber stimulation and contribute to the complex spike waveform, by influencing the number and timing of spikelets, as well as the afterdepolarization plateau (Piochon et al., 2007). Thus, in mature Purkinje cells, functional NMDA receptors are expressed at climbing fiber synapses, and might well contribute to climbing fiberevoked calcium signaling.

\section{METABOTROPIC GLUTAMATE RECEPTORS}

Similar to parallel fiber burst stimulation, climbing fiber stimulation can evoke a slow excitatory current that is triggered by the activation of type 1 metabotropic glutamate receptors (mGluR1) and can be significantly enhanced when glutamate uptake is blocked (Dzubay and Otis, 2002). Such mGluR1-mediated potentials are also evoked by climbing fiber stimulation in the presence of an $\mathrm{mGluR}$ agonist in the bath, suggesting agonist binding and a widespread, dendritic calcium transient as key triggers for this type of slow excitatory signaling (Yuan et al., 2007). In this scenario, climbing fiber activity could facilitate mGluR1 potentials well beyond the climbing fiber input territory, providing that the climbing fiber-evoked calcium signal coincides with sufficiently high local glutamate transients. A related phenomenon has been described earlier, in which parallel fiber activation elicits mGluR1 potentials when the climbing fiber input was stimulated up to $90 \mathrm{~s}$ prior to the parallel fiber input (Batchelor and Garthwaite, 1997). Adding the calcium chelator EGTA to the recording electrode abolished the slow potentials, while they could be triggered when substituting photolytic calcium uncaging for climbing fiber stimulation. The examples provided in these studies (Batchelor and Garthwaite, 1997; Yuan et al., 2007) show that calcium signaling is required to trigger mGluR1 potentials. Recent evidence suggests that this calcium sensitivity results from the involvement of TRPC cation channels that mediate the slow, excitatory conductances. Both TRPC1 (Kim et al., 2003) and TRPC3 channels (Hartmann et al., 2008) have been suggested to 
mediate the slow current. TRPC channels open in response to G-protein-coupled receptor activation and/or the occurrence of calcium surges. This activation pattern principally enables TRPC channels to mediate capacitive calcium entry after release of calcium from intracellular stores (Montell et al., 2002). However, the calcium transient associated with slow, mGluR1 potentials is not blocked in Purkinje cells obtained from TRPC $1^{-1-}$ or TRPC $3^{-1-}$ mice (Hartmann et al., 2008). These observations suggest that mGluR1 potentials might be triggered by calcium surges, but that significant components of the associated calcium influx are not contributed by TRPC channels.

These novel findings are crucial for the present discussion of the consequences of climbing fiber signaling for cerebellar plasticity and function, because mGluR1 potentials significantly enhance complex spike associated calcium transients (Yuan et al., 2007), and might therefore facilitate the induction of parallel fiber LTD. It has been suggested that such an increase in the LTD induction probability occurs when mGluR1 potentials are enhanced after blockade of glutamate transporters (Brasnjo and Otis, 2001). However, the cause for the enhanced probability of LTD induction remains unclear. Both TRPC channels (but see Hartmann et al., 2008) and $\mathrm{IP}_{3}$-mediated calcium release from internal stores could contribute to more pronounced calcium signaling. Moreover, a stronger mGluR1 activation would also result in enhanced PKC activation. All of these factors could enhance the LTD induction probability. Despite of these remaining uncertainties with regard to the type of TRPC channels involved and the origin of the calcium signal associated with slow excitatory potentials, new aspects of mGluR1 signaling at climbing fiber synapses emerge. First, mGluR1-triggered potentials can be evoked by climbing fiber signaling, and second, these slow potentials enhance calcium signaling and are likely to facilitate LTD induction.

\section{PLASTICITY OF CLIMBING FIBER-PURKINJE CELL SYNAPSES}

Marr-Albus-Ito models of cerebellar motor learning describe the parallel fiber input to Purkinje cells as the site in the cerebellar network at which the learning events take place (Albus, 1971; Ito, 1984; Marr, 1969). In these classic models, the climbing fiber plays a crucial role as well, but is seen as a 'teacher' that signals errors and disturbances in sensomotoric function, rather than an additional site of information storage. The long prevailing dogma of the 'invariant' climbing fiber response resulted from the high probability of release at climbing fiber terminals (Dittman and Regehr, 1998; Hashimoto and Kano, 1998; Silver et al., 1998), as well as the all-or-none character of climbing fiber signaling (Eccles et al., 1966). These features make climbing fiber transmission both extremely reliable and forceful, and distinguish it from transmission at most other types of central nervous system synapses.

Nevertheless, synaptic plasticity exists at climbing fiber synapses as well: LTD of climbing fiber EPSCs (recorded in voltage-clamp mode) can be induced using low-frequency ( $5 \mathrm{~Hz}, 30 \mathrm{~s})$ climbing fiber stimulation (Carta et al., 2006; Hansel and Linden, 2000). In current-clamp mode, LTD is associated with an alteration in the complex spike waveform (Hansel and Linden, 2000), a reduction in the complex spike afterhyperpolarization (Schmolesky et al., 2005), and a long-term depression of climbing fiber evoked calcium transients (Weber et al., 2003). Figure 3 illustrates two crucial aspects of climbing fiber LTD: climbing fiber tetanization leads to a reduction in the amplitude of the slow spikelets that make up the late component of a complex spike (Figure 3A), and the associated calcium transients (Figure 3B). Climbing fiber LTD is postsynaptically induced and expressed (Shen et al., 2002). The biochemical cascade for the induction of climbing fiber LTD shares elements with the LTD induction cascade at parallel fiber synapses: at both types of synapses, a postsynaptic calcium surge, activation of $\mathrm{mGluR} 1$ receptors, and activation of protein kinase $\mathrm{C}$ (PKC) are required for LTD induction (Hansel and Linden, 2000). Climbing fiber LTD induction is also PKA-dependent (Schmolesky et al., 2007), which has not been tested for parallel fiber LTD yet.

It remains to be determined whether climbing fiber plasticity can play a similar role in motor learning as assumed for parallel fiber LTD. However, the reduction of calcium transients accompanying climbing fiber LTD (Weber et al., 2003) has a significant effect on the LTD induction probability at parallel fiber synapses (Coesmans et al., 2004) and might therefore provide a critical component of cerebellar gain control (see below).

\section{DEVELOPMENTAL CLIMBING FIBER PLASTICITY}

Climbing fiber synaptic plasticity has also been observed in the developing cerebellum, where it might play a role in the activitydependent elimination of surplus climbing fibers, and the stabilization of the remaining 'winner' climbing fiber input. This pruning process is typically completed at the end of the third postnatal week (Crépel et al., 1976; Lohof et al., 1996). Recent studies suggest that long-term potentiation (LTP) and LTD can be observed at climbing fiber synapses during postnatal development (Bosman et al., 2008; Ohtsuki and Hirano, 2008). In P4-11 Purkinje cells, pairing of climbing fiber stimulation and Purkinje cell depolarization leads to LTP at 'large' climbing fiber inputs, which are sufficiently strong to evoke spike firing in Purkinje cells, but induces LTD at 'small' climbing fiber inputs (Bosman et al., 2008). As multiple climbing fiber inputs share innervation fields on Purkinje cell dendrites (Scelfo et al., 2003; Sugihara, 2005), it is conceivable that LTP and LTD at developing climbing fiber synapses reflect a direct synaptic competition of neighbouring climbing fiber inputs, at the end of which the potentiated input is stabilized and becomes the 'winner', whereas the depressed synaptic inputs are eventually eliminated (Bosman et al., 2008). The LTP described in this study is calciumdependent, but does not require the activation of NMDA receptors. The potentiation is mediated by an increase in the single channel conductance of AMPA receptors, suggesting a postsynaptic induction and expression mechanism (Bosman et al., 2008). Another study also described that in postnatal development (P5-9), climbing fiber stimulation leads to LTP at strong climbing fiber inputs, and LTD at weak climbing fiber inputs (Ohtsuki and Hirano, 2008). In this study, however, LTP and LTD were accompanied by changes in the paired-pulse depression ratio and alterations in the frequency of asynchronous EPSCs, indicating that both types of plasticity are presynaptically expressed. LTP (but not LTD) induction requires a postsynaptic calcium transient, suggesting the involvement of a retrograde messenger (Ohtsuki and Hirano, 2008). Whether or not the different observations made in these two studies can be explained by slight differences in the stimulation protocols (for example, the second study applied unpaired 


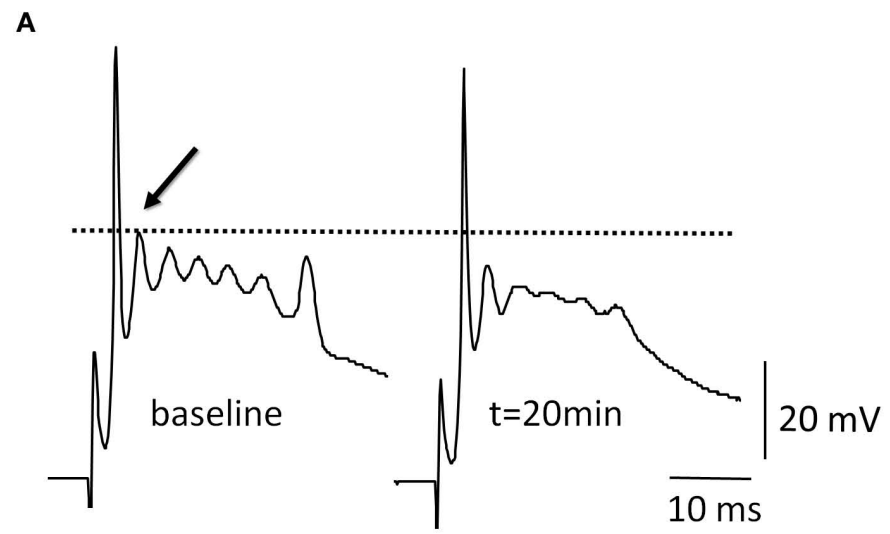

C

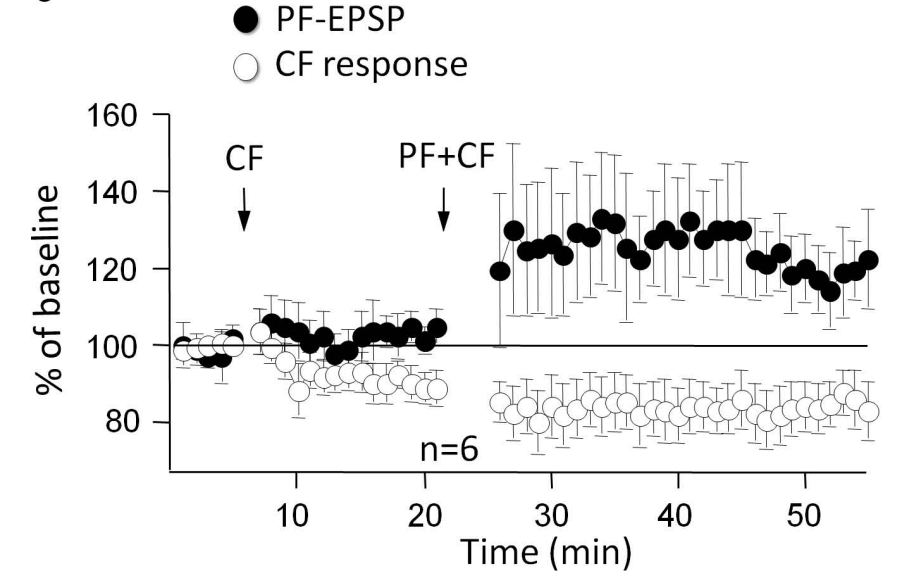

B

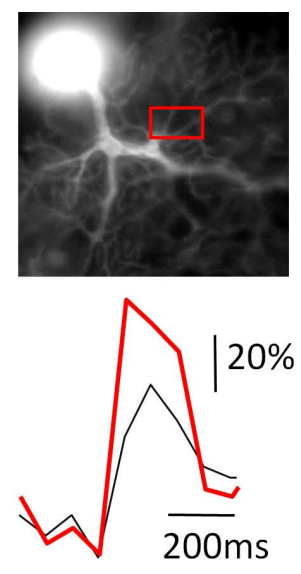

D

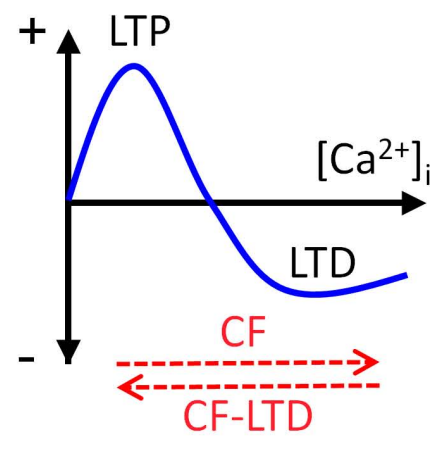

FIGURE 3 | Climbing fiber LTD affects bidirectional parallel fiber plasticity. (A) A 5- $\mathrm{Hz}$ climbing fiber tetanization for $30 \mathrm{~s}$ evokes climbing fiber LTD, which is monitored here as a reduction in the amplitude of the first slow spike component (arrow). (B) Climbing fiber LTD is accompanied by a reduction in complex spike-associated calcium transients (red trace: before climbing fiber tetanization). Calcium transients were recorded in the region of interest (red box). Fluorescence signals were monitored using a cooled CCD camera (Quantix, Roper Scientific), and the calcium indicator dye Oregon Green BAPTA-2 $(200 \mu M)$. (C) After induction of climbing fiber LTD (open dots; CF stimulation at $5 \mathrm{~Hz}, 30 \mathrm{~s}$ ), subsequent application of the parallel fiber LTD protocol (PF + CF stimulation at $1 \mathrm{~Hz}, 5 \mathrm{~min}$ ) induces LTP instead (closed dots). (D) 'Inverse' calcium thresholds in the cerebellum: a higher calcium threshold has to be reached for LTD than for LTP induction. Climbing fiber stimulation contributes calcium to reach this higher threshold, whereas climbing fiber LTD lowers the amplitude of this calcium transient (red arrows). (A), (C) and (D) are modified from Coesmans et al. (2004). Copyright 2004 by Elsevier. (B) is modified from Weber et al. (2003). Copyright 2003 by the National Academy of Sciences, USA. climbing fiber stimulation) remains to be determined. Despite of the existing discrepancies, both Bosman et al. (2008) and Ohtsuki and Hirano (2008) show that bidirectional climbing fiber plasticity exists during postnatal development. These forms of climbing fiber plasticity might be critically involved in the elimination of surplus climbing fibers.

\section{PARALLEL FIBER PLASTICITY UNDER HETEROSYNAPTIC CLIMBING FIBER CONTROL}

The classic Marr-Albus-Ito theories of cerebellar motor learning suggest that synaptic plasticity at parallel fiber synapses (the learning site) depends on activity at the heterosynaptic climbing fiber synapses (the instructor site). In agreement with this theoretical framework, Masao Ito and colleagues described in the early 1980s a form of LTD at parallel fiber synapses that is induced following paired parallel fiber and climbing fiber activity (Ito and Kano, 1982; Ito et al., 1982). As first suggested by Albus (Albus, 1971), parallel fiber LTD provides an attractive candidate mechanism for cerebellar motor learning, as it is expected to result in a disinhibition of the target cells of inhibitory Purkinje cell projections in the deep cerebellar nuclei (DCN) or vestibular nuclei.

Parallel fiber LTD induction depends on activation of the mGluR1/ PKC signaling cascade (for review see Hansel and Bear, 2008) and activation of the $\alpha$ isoform of calcium/calmodulin-dependent kinase II ( $\alpha$ CaMKII; Hansel et al., 2006). Climbing fiber signaling triggers dendritic calcium transients and contributes to parallel fiber LTD induction (Konnerth et al., 1992) by activating these induction cascades. Co-activation of parallel fiber and climbing fiber inputs causes 
supralinear calcium signaling in parallel fiber spines (Wang et al., 2000), thus providing a coincidence detection mechanism that might be required to reach a critical calcium threshold for LTD induction. A somewhat puzzling observation has been that strong parallel fiber activation on its own can trigger parallel fiber LTD in the absence of climbing fiber activity (Eilers et al., 1997; Hartell, 1996). Similarly, climbing fiber stimulation can be replaced by somatic depolarization (Linden et al., 1991). These findings suggest that climbing fiber activity indeed facilitates LTD induction by amplifying local calcium transients, but that there is no specific requirement for climbing fiber-evoked calcium signals. This conclusion is supported by recent recordings from cerebellar Purkinje cells of mormyrid fish (introduced above). Parallel fiber stimulation alone at enhanced stimulus strength (increase in the pulse duration) can induce parallel fiber LTD. When the climbing fiber is co-stimulated, however, a lower stimulus strength (as applied to monitor test responses before and after tetanization) is sufficient for LTD induction (Han et al., 2007). These observations suggest that parallel fiber LTD can be induced in the absence of climbing fiber activity, which might nevertheless have an important role in facilitating the induction process.

The impact of climbing fiber signaling on parallel fiber plasticity becomes more obvious when taking LTP into consideration. Both pre- and postsynaptically expressed types of LTP have been described at parallel fiber synapses (Lev-Ram et al., 2002; Salin et al., 1996). LTP can be induced when applying the same lowfrequency/low-intensity parallel fiber stimulation protocol used for LTD induction, when climbing fiber stimulation is omitted (Lev-Ram et al., 2002). Just like LTD, this form of LTP is postsynaptically induced and expressed (Coesmans et al., 2004; Lev-Ram et al., 2002) and might therefore function as a reversal mechanism for LTD. LTP induction depends on lower calcium transients than LTD induction (Coesmans et al., 2004; Figure 3D), and requires the activation of protein phosphatases PP1, PP2A and PP2B (Belmeguenai and Hansel, 2005). Therefore, at the level of calcium signaling and kinase/phosphatase activation requirements, cerebellar bidirectional synaptic plasticity seems to be governed by induction rules that provide a mirror image of those described at glutamatergic synapses in hippocampal and neocortical pyramidal cells (Jörntell and Hansel, 2006). Moreover, a unique motif in cerebellar plasticity is the heterosynaptic control of parallel fiber plasticity by the climbing fiber input. The efficacy of this control function becomes obvious when looking at the consequences of LTD at the climbing fiber input itself (Hansel and Linden, 2000). Climbing fiber LTD is accompanied by a reduction in complex spike-associated calcium transients (Weber et al., 2003). This reduction in calcium signaling is sufficiently strong to reverse the polarity of parallel fiber plasticity after previous climbing fiber LTD induction (Coesmans et al., 2004). This metaplastic interaction is illustrated in Figure 3C: when climbing fiber LTD is induced first, subsequent application of the parallel fiber LTD induction protocol results in LTP induction instead. The most likely explanation for this sign reversal is that climbing fiber LTD reduced the activitydependent calcium signal below the threshold for LTD induction (Figure 3D).

In addition to its role in postsynaptic parallel fiber plasticity, climbing fiber signaling also affects a form of presynaptic parallel fiber LTP that results from brief parallel fiber tetanization (e.g. $8 \mathrm{~Hz}$ for $15 \mathrm{~s}$; Salin et al., 1996). Presynaptic parallel fiber LTP is induced by activation of adenylyl cyclase I (Storm et al., 1998), production of cAMP and the subsequent activation of cAMP-dependent protein kinase (PKA; Chen and Regehr, 1997; Salin et al., 1996). More recent observations show that climbing fiber-evoked calcium signaling can trigger the release of endocannabinoids from Purkinje cell dendrites (Brenowitz and Regehr, 2003), which bind to CB1 receptors at parallel fiber terminals and suppress LTP induction by interfering with the adenylyl cyclase/PKA cascade (Van Beugen et al., 2006). It has been suggested that endocannabinoid signaling facilitates the induction of postsynaptic LTD (Safo and Regehr, 2005). The inhibitory action of CB1 receptor activation on presynaptic LTP might well contribute to this facilitation of LTD, assuming that activity-dependent postsynaptic alterations are often accompanied by presynaptic changes. In this scenario, climbing fiber-evoked calcium transients do not only promote postsynaptic LTD, but in addition provide a 'safety lock' mechanism that prevents that presynaptic LTP and postsynaptic LTD occur at the same time (Van Beugen et al., 2006). Under some conditions, coincident parallel fiber activity and retrograde endocannabinoid signaling might even promote the induction of a presynaptic form of LTD (Qiu and Knöpfel, 2009), thus aligning pre-and postsynaptic changes. These recent reports show that the climbing fiber input heterosynaptically affects four forms of parallel fiber plasticity: postsynaptic LTD, postsynaptic LTP, presynaptic LTP, and presynaptic LTD.

\section{THE OTHER CLIMBING FIBER SIGNAL: CORTICOTROPIN- RELEASING FACTOR}

The complex spike-associated calcium transients in Purkinje cell dendrites are certainly the best characterized contribution of climbing fiber signaling to cerebellar plasticity. However, it should not be overlooked that climbing fiber activity can additionally result in the release of the neuropeptide corticotropin-releasing factor (CRF) from climbing fiber terminals (Barmack and Young, 1990; Tian and Bishop, 2003). CRF can bind to type 1 and/or type 2 CRF receptors expressed in Purkinje cells. Whereas type 2 CRF receptors are not expressed in spines, type 1 receptors, which are G-protein coupled and lead to the activation of adenylyl cyclase/PKA and PKC pathways (Grammatopoulos et al., 2001), are located in the dendrite across from parallel fiber terminals, and in non-synaptic regions (Swinny et al., 2003). CRF signaling has been shown to be critically involved in parallel fiber LTD induction as the CRF receptor antagonists $\alpha$-helical CRF-(9-41) ( $\alpha$-h CRF) and astressin prevent LTD (Miyata et al., 1999). Type-1 CRF receptors are not expressed in the dendrite across from climbing fiber terminals (Swinny et al., 2003), and yet climbing fiber LTD is blocked, too, in the presence of astressin (Schmolesky et al., 2007), suggesting that diffusion to adjacent receptors is sufficient. It is possible that CRF signaling facilitates LTD induction at both climbing fiber and parallel fiber synapses by activating the PKC signaling cascade and, at least in the case of climbing fiber LTD, the PKA signaling cascade (Schmolesky et al., 2007). These results show that the climbing fiber input exerts a control function over parallel fiber plasticity not only through the calcium transients associated with complex spike activity, but also by the activity-dependent release of the neuropeptide CRF (Figure 4). Moreover, it seems that the same factors involved in parallel fiber LTD (here: high calcium, CRF receptor activation) promote LTD at the climbing fiber input as well. 


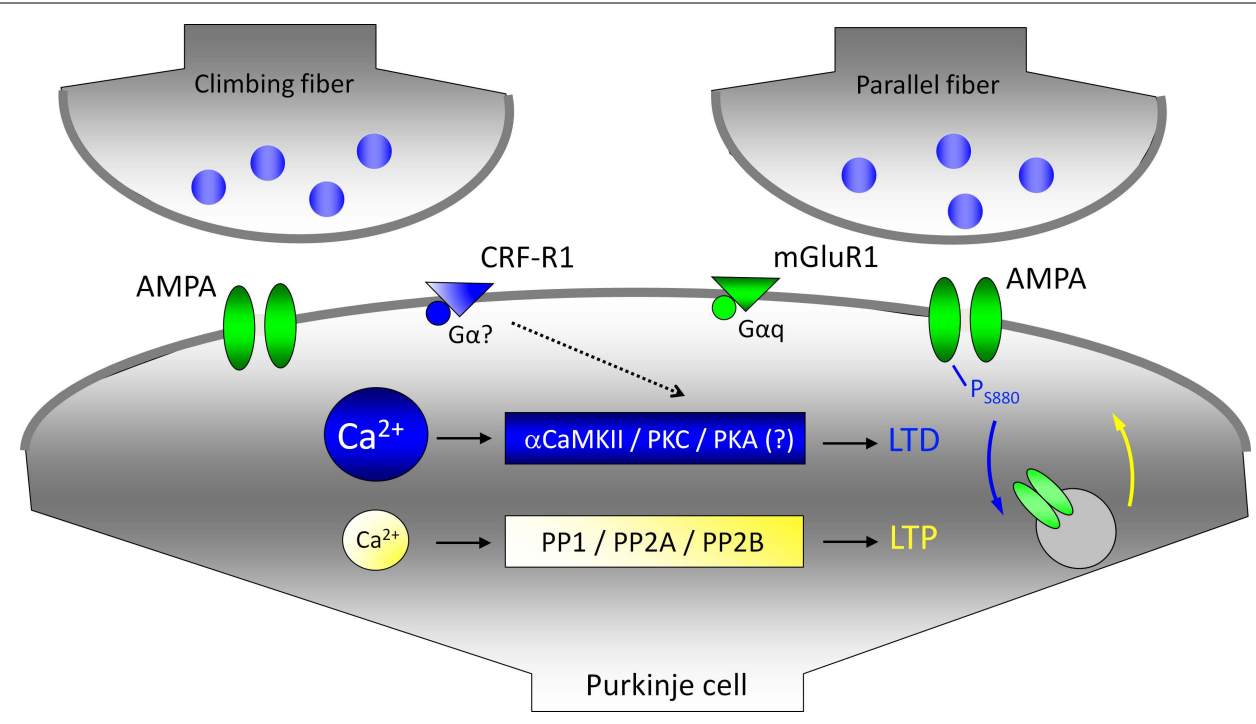

FIGURE 4 | Climbing fiber activity facilitates LTD induction at parallel fiber synapses. For simplicity, climbing fiber and parallel fiber terminals are shown to contact the same postsynaptic compartment. The LTD induction cascade is shown in blue: large calcium transients promote the activation of $\alpha$ CaMKII and PKC. A PKC-mediated phosphorylation of the AMPA receptor subunit GluR2 triggers the internalization of GluR2 subunits. The LTP cascade is shown in yellow: lower calcium transients promote phosphatase activation (only PP2B is directly calcium-regulated). Eventually, GluR2 subunits are delivered to the membrane. Climbing fiber activity facilitates LTD induction by elevating the overall calcium transient (calcium sources are not shown), and by releasing the neuropeptide CRF. CRF binding to type 1 CRF receptors (CRF-R1) facilitates the activation of PKC and PKA. The activation of PKA is a required step for the induction of climbing fiber LTD. It has not been determined yet, whether the same holds true for parallel fiber LTD.

\section{IS CLIMBING FIBER SIGNALING INVOLVED IN CEREBELLAR MOTOR LEARNING?}

Numerous studies using genetically modified mice suggest a correlation between parallel fiber LTD and cerebellar motor learning (De Zeeuw and Yeo, 2005). However, LTD has never been demonstrated during motor learning in behaving animals. It has indeed been claimed that parallel fiber LTD might not be involved in motor learning at all, based on the observation that motor learning (eyeblink conditioning) is intact when parallel fiber LTD is pharmacologically inhibited (Welsh et al., 2005). Even if LTD is involved in motor learning, the contribution of the climbing fiber input remains unclear, as LTD can be induced in the absence of climbing fiber activity, as long as the parallel fiber input is sufficiently active (Eilers et al., 1997; Han et al., 2007; Hartell, 1996). Moreover, when reviewing recent developments in cerebellar plasticity research, it becomes obvious that several types of plasticity that have been characterized do not require climbing fiber activity for induction. This holds true for presynaptic LTP (Salin et al., 1996) and postsynaptic LTP (Lev-Ram et al., 2002). Climbing fiber activity is only required for the induction of LTD at both climbing fiber (Hansel and Linden, 2000) and parallel fiber inputs (Ito and Kano, 1982; Ito et al., 1982) as well as for rebound potentiation at interneuron - Purkinje cell synapses (Kano et al., 1992). While climbing fiber activity-dependent parallel fiber LTD has been the predominant model for cerebellar motor learning, these more recently discovered types of plasticity could well be involved in cerebellar learning as well, but are independent of climbing fiber activity.

So what is the role of parallel fiber plasticity, and specially climbing fiber activity-dependent parallel fiber plasticity, in cerebellar motor learning? To slightly clear the fog, it might be useful to take a step back and have a look at the evidence at hand. Granule cells provide massive excitatory input to Purkinje cells via ascending granule cell axons on the one hand, and parallel fiber synapses on the other. These two sets of granule cell input, however, seem to play different roles in cerebellar processing and gain control. Synapses of the ascending axons do not show forms of long-term plasticity (Sims and Hartell, 2006). In contrast, there is a high degree of pre-and postsynaptic plasticity at parallel fiber synapses, but about $85 \%$ of these synapses are functionally silent (Isope and Barbour, 2002). It has therefore been suggested that granule cells predominantly activate Purkinje cells through the hardwired ascending axon input, while the parallel fiber input allows for acquired control using fine-tuned recruiting of parallel fiber synapses (Rokni et al., 2008). These observations suggest a high degree of functional specialization of the two different sets of synaptic contacts provided by granule cells, and support the view that the parallel fiber system plays a key role in cerebellar adaptations. But under what conditions does parallel fiber plasticity occur, and what are its functional consequences? A very elegant study has been provided by Jörntell and Ekerot, who showed that parallel fiber receptive fields in adult cats can be bidirectionally modified after parallel fiber stimulation in vivo (Jörntell and Ekerot, 2002). Paired parallel fiber and climbing fiber stimulation causes a long-term decrease in the receptive field size of Purkinje cells, while unpaired parallel fiber stimulation causes a lasting increase. While this study provides an example of plasticity of sensory inputs to cerebellar Purkinje cells, without immediately obvious consequences for motor control, there are three aspects that are highly relevant for the present discussion. First, the stimulus 
protocols applied suggest that both LTD (paired stimulation) and LTP (unpaired stimulation) phenomena contribute to the decrease and increase, respectively, of the receptive field sizes. If so, this study demonstrates that LTD and LTP are involved in a form of cerebellar learning that can be monitored in vivo. Second, this study elegantly shows that LTD and LTP can perfectly complement each other in cerebellar information storage, without the need to classify one as the 'learning' mechanism and the other as a tool used for 'extinction' or 'reversal'. In other words, in some types of cerebellar learning, depression and potentiation simply provide two sides of the same coin, allowing for bidirectional adaptations. Third, this study clearly demonstrates that climbing fiber activity exerts a crucial function in the control of bidirectional cerebellar plasticity. This latter observation is in line with the widespread notion that enhanced climbing fiber activity precedes cerebellar learning, acting as an 'error detector', or as a 'teacher' (for review see Simpson et al., 1996). In this view, climbing fiber activity signals the need for adjusting the gain values of cerebellar sensory inputs and/or motor output control.

\section{CONCLUSION}

In a recent paper published in Frontiers in Neuroscience, Rodolfo Llinas and Yosef Yarom review the histology and physiology of the cerebellar cortex, concluding that 'the cerebellum should be regarded as a control machine rather than a learning machine' (Rokni et al., 2008). We do not agree with this assessment. In our view, the cerebellum certainly acts as a control machine, but on top of that the cerebellum (particularly the cerebellar cortex) provides a giant switchboard for associative learning. Currently, the existing evidence does not seem to allow for a definite conclusion. Our more learning-biased view results from close inspection of the cerebellar circuitry and its capacity for information storage based on both in vitro and in vivo studies (see also Hansel et al., 2001; Jörntell and Hansel, 2006). Parallel fiber to Purkinje cell synapses are perfect candidate locations for the storage of motor memories, because of their ability to bidirectionally adjust synaptic gain both pre- and postsynaptically. Although not strictly required, elevated climbing fiber activity facilitates the induction of parallel fiber LTD by enhancing dendritic calcium signals and by releasing the neuropeptide CRF from climbing fiber terminals. Climbing fiber activity also suppresses presynaptic LTP by triggering the release of endocannabinoids from Purkinje cell dendrites. The complexity of this 'orchestration' of parallel fiber plasticity by the climbing fiber input shows after induction of LTD at the climbing fiber input itself: the accompanying reduction in complex spike-associated calcium transients shifts the relative probabilities for the induction of LTD and LTP, respectively, at the parallel fiber input. Plasticity residing at the parallel fiber synapses is likely complemented by additional types of cerebellar plasticity, such as plasticity at inhibitory synapses onto Purkinje cells, and intrinsic plasticity mechanisms found in several types of neurons within the cerebellum. It remains to be seen how the cerebellum puts these features to use, but its underlying circuitry seems very well suited for activity-dependent information storage and learning.

\section{ACKNOWLEDGMENTS}

We would like to thank Qionger He for invaluable comments on the manuscript. The authors were supported by a Japanese Society for the Promotion of Science fellowship JSPS 02714 to G.O., a National Institute of Neurological Disorders and Stroke grant NS-62771 to C.H., and a Netherlands Organization for Scientific Research grant NWO-ALW 817-02-013 to C.H.

\section{REFERENCES}

Akazawa, C., Shigemoto, R., Bessho, Y., Nakanishi, S., and Mizuno, N. (1994). Differential expression of five $\mathrm{N}$ methyl-D-aspartate receptor subunit mRNAs in the cerebellum of developing and adult rats. J. Comp. Neurol. 347, 150-160.

Albus, J. S. (1971). A theory of cerebellar function. Math. Biosci. 10, 25-61.

Barmack, N. H., and Young, W. S. (1990). Optokinetic stimulation increases corticotropin-releasing factor mRNA in inferior olivary neurons of rabbits. $J$. Neurosci. 10, 631-640.

Batchelor, A. M., and Garthwaite, J. (1997). Frequency detection and temporally dispersed synaptic signal association through a metabotropic glutamate receptor pathway. Nature 385, 74-77.

Belmeguenai, A., and Hansel, C. (2005). A role for protein phosphatases 1,2A, and $2 \mathrm{~B}$ in cerebellar long-term potentiation. J. Neurosci. 25, 10768-10772.

Bliss, T. V. P., and Collingridge, G. L. (1993). A synaptic model of memory: long-term potentiation in the hippocampus. Nature 361, 31-39.
Bosman, L. W., Takechi, H., Hartmann, J., Eilers, J., and Konnerth, A. (2008). Homosynaptic long-term synaptic potentiation of the 'winner' climbing fiber synapse in developing Purkinje cells. J. Neurosci. 28, 798-807.

Brasnjo, G., and Otis, T. S. (2001). Neuronal glutamate transporters control activation of postsynaptic metabotropic glutamate receptors and influence cerebellar long-term depression. Neuron 31, 607-616.

Brenowitz, S. D., and Regehr, W. G. (2003). Calcium dependence of retrograde inhibition by endocannabinoids at synapses onto Purkinje cells. J. Neurosci. 23, 6373-6384.

Carta,M.,Mameli,M.,andValenzuela, C. F. (2006). Alcohol potently modulates climbing fiber-Purkinje neuron synapses: role of metabotropic glutamate receptors. J. Neurosci. 26, 1906-1912.

Chen, C., and Regehr, W. G. (1997). The mechanism of cAMP-mediated enhancement at a cerebellar synapse. J. Neurosci. 17, 8687-8694.

Coesmans, M., Weber,J.T., DeZeeuw, C. I., and Hansel, C. (2004). Bidirectional parallel fiber plasticity in the cerebellum under climbing fiber control. Neuron 44, 691-700.

Crépel, F., Mariani, J., and DelhayeBouchaud, N. (1976). Evidence for a multiple innervation of Purkinje cells by climbing fibers in the mature rat cerebellum. J. Neurobiol. 7, 567-578.

Davie, J. T., Clark, B. A., and Häusser, M (2008). The origin of the complex spike in cerebellar Purkinje cells. $J$. Neurosci. 28, 7599-7609.

De Zeeuw, C. I., and Yeo, C. H. (2005) Time and tide in cerebellar memory formation. Curr. Opin. Neurobiol. 15, 667-674.

Dittman, J. S., and Regehr, W. G. (1998) Calcium dependence and recovery kinetics of presynaptic depression at the climbing fiber to Purkinje cell synapse. J. Neurosci. 18, 6147-6162.

Dzubay, J. A., and Otis, T. S. (2002) Climbing fiber activation of metabotropic glutamate receptors on cerebellar Purkinje neurons. Neuron 36 1159-1167.

Eccles, J. C., Llinas, R., and Sasaki, K. (1964). Excitation of cerebellar
Purkinje cells by the climbing fibres. Nature 203, 245-246.

Eccles, J. C., Llinas, R., and Sasaki, K. (1966). The excitatory synaptic action of climbing fibres on the Purkinje cells of the cerebellum. J. Physiol. 182, 268-296.

Eilers, J., Takechi, H., Finch, E. A., Augustine, G. J., and Konnerth, A. (1997). Local dendritic Ca2+ signaling induces cerebellar long-term depression. Learn. Mem. 3, 159-168.

Ekerot, C. F., Oscarsson, O., and Schouenborg, J. (1987). Stimulation of cat cutaneous nociceptive $\mathrm{C}$ fibres causing tonic and synchronous activity in climbing fibres. J. Physiol. 386, 539-546.

Farrant, M., and Cull-Candy, S. G. (1991). Excitatory amino acid receptor-channels in Purkinje cells in thin cerebellar slices. Proc. R. Soc. Lond. B Biol. Sci. 244, 179-184.

Grammatopoulos, D. K., Randeva, H. S., Levine, M. A., Kanellopoulou, K. A., and Hillhouse, E. W. (2001). Rat cerebral cortex corticotropin-releasing hormone receptors: evidence for 
receptor coupling to multiple G-proteins. J. Neurochem. 76, 509-519.

Han, V.Z.,Zhang, Y., Bell,C.C., and Hansel, C. (2007). Synaptic plasticity and calcium signaling in Purkinje cells of the central cerebellar lobes of mormyrid fish. J. Neurosci. 27, 13499-13512.

Hansel, C., and Linden, D. J. (2000). Long-term depression of the cerebellar climbing fiber - Purkinje neuron synapse. Neuron $26,473-482$.

Hansel, C., Linden, D. J., and D'Angelo, E. (2001). Beyond parallel fiber LTD: the diversity of synaptic and non-synaptic plasticity in the cerebellum. Nat. Neurosci. 4, 467-475.

Hansel, C., De Jeu, M., Belmeguenai, A., Houtman, S. H., Buitendijk, G. H., Andreev, D., De Zeeuw, C. I., and Elgersma, Y. (2006). $\alpha$ CaMKII is essential for cerebellar LTD and motor learning. Neuron 51, 835-843.

Hansel, C., and Bear, M. F. (2008). LTD - Synaptic depression and memory storage. In J. D. Sweatt (Ed.), Molecular Mechanisms of Memory. Vol. [4] of Learning and Memory: A Comprehensive Reference, 4 vols, J. Byrne, ed. (Oxford, Elsevier), pp. 327-366.

Hartell, N. A. (1996). Strong activation of parallel fibers produces localized calcium transients and a form of LTD that spreads to distant synapses. Neuron 16, 601-610.

Hartmann, J., Dragicevic, E., Adelsberger, H., Henning, H. A., Sumser, M., Abramowitz, J., Blum, R., Dietrich, A., Freichel, M., Flockerzi, V., Birnbaumer, L., and Konnerth, A. (2008). TRPC 3 channels are required for synaptic transmission and motor coordination. Neuron 59, 392-398.

Hashimoto, K., and Kano, M. (1998). Presynaptic origin of paired-pulse depression at climbing fiber-Purkinje cell synapses in the rat cerebellum. $J$. Physiol. 506, 391-405.

Hollmann, M., Hartley, M., and Heinemann, S. (1991). Ca2+ permeability of KA-AMPA-gated glutamate receptor channels depends on subunit composition. Science 252, 851-853.

Isope, P., and Barbour, B. (2002). Properties of unitary granule cell to Purkinje cell synapses in adult rat cerebellar slices. J. Neurosci. 22, 9668-9678.

Ito, M., Sakurai, M., and Tongroach, P. (1982). Climbing fibre induced depression of both mossy fibre responsiveness and glutamate sensitivity of cerebellar Purkinje cells. J. Physiol. 324, 113-134.

Ito, M., and Kano, M. (1982). Long-lasting depression of parallel fiber-Purkinje cell transmission induced by conjunctive stimulation of parallel fibers and climbing fibers in the cerebellar cortex. Neurosci. Lett. 33, 253-258.

Ito, M. (1984). The Cerebellum and Neural Control. New York, Raven Press.

Jörntell, H, and Ekerot, C. F. (2002). Reciprocal bidirectional plasticity of parallel fiber receptive fields in cerebellar Purkinje cells and their afferent interneurons. Neuron 34, 797-806.

Jörntell, H., and Hansel, C. (2006). Synaptic memories upside down: bidirectional plasticity at cerebellar parallel fiber-Purkinje cell synapses. Neuron 52, 227-238.

Kano, M., Rexhausen, U., Dreessen, J., and Konnerth, A. (1992). Synaptic excitation produces a long-lasting rebound potentiation of inhibitory synaptic signals in cerebellar Purkinje cells. Nature 356, 601-604.

Kim,S.J., Kim,Y.S.,Yuan,J.P.,Petralia, R. S., Worley, P. F., and Linden, D. J. (2003). Activation of TRPC1 cation channel by metabotropic glutamate receptor mGluR1. Nature 426, 285-291.

Konnerth, A., Llano, I., and Armstrong, C. M. (1990). Synaptic currents in cerebellar Purkinje cells. Proc. Natl. Acad. Sci. U.S.A. 87, 2662-2665.

Konnerth, A., Dreessen, J., and Augustine, G. J. (1992). Brief dendritic calcium signals initiate long-lasting synaptic depression in cerebellar Purkinje cells. Proc. Natl. Acad. Sci. U.S.A. 89, 7051-7055.

Lachamp, P., Balland, B., Tell, F., Baude, A., Strube, C., Crest, M., and Kessler, J. P. (2005). Early expression of AMPA receptors and lack of NMDA receptors in developing rat climbing fibre synapses. J. Physiol. 564, 751-763.

Lev-Ram, V., Wong, S. T., Storm, D. R., and Tsien, R. Y. (2002). A new form of cerebellar long-term potentiation is postsynaptic and depends on nitric oxide, but not cAMP. Proc. Natl. Acad. Sci. U.S.A. 99, 8389-8393.

Linden, D. J., Dickinson, M. H., Smeyne, M., and Connor, J.A. (1991). A long-term depression of AMPA currents in cultured cerebellar Purkinje neurons. Neuron 7, 81-89.

Llano, I., Marty, A., Armstrong, C. M., and Konnerth, A. (1991). Synaptic- and agonist-induced excitatory currents of Purkinje cells in rat cerebellar slices. J. Physiol. 434, 183-213.

Llinas, R., and Sugimori, M. (1980). Electrophysiological properties of in vitro Purkinje cell dendrites in mammalian cerebellar slices. J. Physiol. 305, 197-213.

Loewenstein,Y.,Mahon,S.,Chadderton, P., Kitamura, K., Sompolinsky, H., Yarom, Y., and Häusser, M. (2005). Bistability of cerebellar Purkinje cells modulated by sensory stimulation. Nat. Neurosci. 8, 202-211.

Lohof,A.M., Delhaye-Bouchaud, N., and Mariani, J. (1996). Synapse elimination in the central nervous system: functional significance and cellular mechanisms. Rev. Neurosci. 7, 85-101.

Marr, D. (1969). Theory of cerebellar cortex. J. Physiol. 202, 437-470.

Maruta, J., Hensbroek, R. A., and Simpson, J. I. (2007). Intraburst and interburst signaling by climbing fibers. J. Neurosci. 27, 11263-11270.

Miyakawa H., Lev-Ram, V., LasserRoss, N., and Ross, W. N. (1992). Calcium transients evoked by climbing fiber and parallel fiber synaptic inputs in guinea pig cerebellar Purkinje neurons. J. Neurophysiol. 68, 1178-1189.

Miyata, M., Okada, D., Hashimoto, K., Kano, M., and Ito, M. (1999). Corticotropin-releasing factor plays a permissive role in cerebellar long-term depression. Neuron 22, 763-775.

Momiyama, A., Feldmeyer, D., and CullCandy, S. G. (1996). Identification of a native low-conductance NMDA channel with reduced sensitivity to $\mathrm{Mg} 2+$ in rat central neurones. J. Physiol. 494, 479-492.

Montell, C., Birnbaumer, L., and Flockerzi, V. (2002). The TRP channels, a remarkably functional family. Cell 108, 595-598.

Monyer, H., Sprengel, R., Schoepfer, R., Herb, A., Higuchi, M., Lomeli, H., Burnashev, N., Sakmann, B., and Seeburg, P. H. (1992). Heteromeric NMDA receptors: molecular and functional distinction of subtypes. Science 256, 1217-1221.

Monyer, H., Burnashev, N., Laurie, D. J., Sakmann, B., and Seeburg,P.H.(1994). Developmental and regional expression in the rat brain and functional properties of four NMDA receptors. Neuron 12, 529-540.

Moriyoshi, K., Masu, M., Ishii, T., Shigemoto, R., Mizumo, N., and Nakanishi, S. (1991). Molecular cloning and characterization of the rat NMDA receptor. Nature 354, 31-37.

Ohtsuki, G., and Hirano, T. (2008). Bidirectional plasticity at developing climbing fiber-Purkinje neuron synapses. Eur. J. Neurosci. 28, 2393-2400.

Palay, S. L., and Chan-Palay, V. (1974). Cerebellar Cortex. New York, Springer.

Perkel, D. J., Hestrin, S., Sah, P., and Nicoll, R. A. (1990). Excitatory synaptic currents in Purkinje cells. Proc. $R$. Soc. Lond. B Biol. Sci. 241, 116-121.

Petralia, R., Yokotani, N., and Wenthold, R. (1994).Light and electron miscroscope distribution of the NMDA receptor subunit NMDAR1 in the rat nervous system using a selective anti-peptide antibody. J. Neurosci. 14, 667-696.

Piochon, C., Irinopoulou, T., Brusciano, D., Bailly, Y., Mariani, J., and Levenes, C. (2007). NMDA receptor contribution to the climbing fiber response in the adult mouse Purkinje cell. J. Neurosci. 27, 10797-10809.

Qiu, D. L., and Knöpfel, T. (2009). Presynaptically expressed long-term depression at cerebellar parallel fiber synapses. Pflugers Arch. 457, 865-875.

Ramón y Cajal, S. (1911). Histologie du système nerveux de l'homme et des vertébrés, Vol. II. Paris, Maloine.

Renzi, M., Farrant, M., and CullCandy, S. G. (2007). Climbing fibre activation of NMDA receptors in Purkinje cells of adult mice. J. Physiol. 585.1, 91-101.

Rokni, D., Llinas, R., and Yarom, Y. (2008). The morpho/functional discrepancy in the cerebellar cortex: looks alone are deceptive. Front. Neurosci. 2, 192-198.

Rokni, D., and Yarom, Y. (2009). Statedependence of climbing fiber-driven calcium transients in Purkinje cells. Neuroscience. doi: 10.1016/J.Neuros cience.2008.12.044. [Epub ahead of print].

Ross, W. N., and Werman, R. (1987). Mapping calcium transients in the dendrites of Purkinje cells from the guinea-pig cerebellum in vitro. J. Physiol. 389, 319-336.

Safo, P. K., and Regehr, W. G. (2005). Endocannabinoids control the induction of cerebellar LTD. Neuron 48, 647-659.

Salin, P. A., Malenka, R. C., and Nicoll, R. A. (1996). Cyclic AMP mediates a presynaptic form of LTP at cerebellar parallel fiber synapses. Neuron 16, 797-803.

Scelfo, B., Strata, P., and Knöpfel, T. (2003). Sodium imaging of climbing fiber innervation fields in developing mouse Purkinje cells. J. Neurophysiol. 89, 2555-2563.

Schmolesky, M. T., Weber, J. T., De Zeeuw, C. I., and Hansel, C. (2002). The making of a complex spike: ionic composition and plasticity. Ann. N. Y. Acad. Sci. 978, 359-390.

Schmolesky, M. T., De Zeeuw, C. I., and Hansel, C. (2005). Climbing fiber synaptic plasticity and modifications in Purkinje cell excitability. Prog. Brain Res. 148, 81-94.

Schmolesky, M. T., De Ruiter, M. M., De Zeeuw, C. I., and Hansel, C. (2007). The neuropeptide corticotropin-releasing factor regulates excitatory transmission and plasticity at the climbing fibre - Purkinje 
cell synapse. Eur. J. Neurosci. 25, 1460-1466.

Schonewille, M., Khosrovani, S., Winkelman, B. H., Hoebeek, F. E., De Jeu, M. T., Larsen, I.M., Van den Burg, J., Schmolesky, M. T., Frens, M. A., and De Zeeuw, C. I. (2006). Purkinje cells in awake behaving animals operate at the upstate membrane potential. Nat. Neurosci. 9, 459-461.

Shen, Y., Hansel, C., and Linden, D. J. (2002). Glutamate release during LTD at cerebellar climbing fiber Purkinje cell synapses. Nat. Neurosci. 5, 725-726.

Silver, R. A., Momiyama, A., and CullCandy S. G. (1998). Locus of frequency-dependent depression identified with multiple-probability fluctuation analysis at rat climbing fiber-Purkinje cell synapses. J. Physiol. 510, 881-902.

Simpson, J. I., Wylie, D. R., and De Zeeuw, C. I. (1996). On climbing fiber signals and their consequence(s). Behav. Brain Sci. 19, 384-398.

Sims, R. E., and Hartell, N. A. (2006). Differential susceptibility to synaptic plasticity reveals a functional specialization of ascending axon and parallel fiber synapses to cerebellar Purkinje cells. J. Neurosci. 26, 5153-5159.

Storm, D. R., Hansel, C., Hacker, B., Parent, A., and Linden, D. J. (1998). Impaired cerebellar long-term potentiation in type I adenylyl cyclase mutant mice. Neuron 20, 1199-1210.

Strata, P., and Rossi, F. (1998). Plasticity of the olivocerebellar pathway. Trends Neurosci. 21, 407-413.

Stuart, G., and Häusser, M. (1994). Initiation and spread of sodium action potentials in cerebellar Purkinje cells. Neuron 13, 703-712.

Sugihara, I. (2005). Microzonal projection and climbing fiber remodeling in single olivocerebellar axons of newborn rats at postnatal days 4-7. J. Comp. Neurol. 487, 93-106.

Swinny, J.D., Kalicharan, D., Blaauw, E. H. Ijkema-Paassen,J., Shi, F., Gramsbergen, A., and van der Want, J. J. (2003). Cotricotropin-releasing factor receptor types 1 and 2 are differentially expressed in pre-and postsynaptic elements in the post-natal developing rat cerebellum. Eur. J. Neurosci. 18, 549-562.

Thompson, C. L., Drewery, D. L., Atkins, H. D., Stephenson, F. A., and Chazot, P. L. (2000). Immunohistochemical localization of $\mathrm{N}$-methyl-D-aspartate receptor NR1, NR2A, NR2B and NR2C/D subunits in the adult mammalian cerebellum. Neurosci. Lett. 283, 85-88.

Tian, J. B., and Bishop, G. A. (2003). Frequency-dependent expression of corticotropin releasing factor in the rat's cerebellum. Neuroscience 121, 363-377.

Usowicz, M. M., Sugimori, M., Cherksey, B., and Llinas, R. (1992).
P-type calcium channels in the somata and dendrites of adult cerebellar Purkinje cells. Neuron 9, 1185-1199.

Van Beugen, B. J., Nagaraja, R. Y., and Hansel, C. (2006). Climbing fiberevoked endocannabinoid signaling heterosynaptically suppresses presynaptic cerebellar long-term potentiation. J. Neurosci. 26, 8289-8294.

Wang, S. S. H., Denk, W., and Häusser, M (2000). Coincidence detection in single dendritic spines mediated by calcium release. Nat. Neurosci. 3, 1266-1273.

Watanabe, M., Mishina, M., and Inoue Y. (1994).Distinct spatiotemporal expressions of five NMDA receptor channel subunit mRNAs in the cerebellum. $J$. Comp. Neurol. 343, 513-519.

Watanabe,S., Takagi,H., Miyasho, T., Inoue, M., Kirino, Y., Kudo, Y., and Miyakawa, H. (1998). Differential roles of two types of voltage-gated $\mathrm{Ca}^{2+}$ channels in the dendrites of rat cerebellar Purkinje neurons. Brain Res. 791, 43-55.

Weber, J. T., De Zeeuw, C. I., Linden, D. J., and Hansel, C. (2003). Long-term depression of climbing fiber-evoked calcium transients in Purkinje cell dendrites. Proc. Natl. Acad. Sci. U.S.A. 100, 2878-2883.

Welsh, J. P., Yamaguchi, H., Zeng, X. H., Kojo, M., Nakada, Y., Takagi, A., Sugimori, M., and Llinas, R. R. (2005) Normal motor learning during pharmacological prevention of Purkinje cell long-term depression. Proc. Natl. Acad. Sci. U.S.A. 102, 17166-17171.
Yamada, K., Fukaya, M., Shimizu, H., Sakimura, K., and Watanabe,M. (2001). NMDA receptor subunits GluRepsilon1, GluRepsilon3 and GluRzeta 1 are enriched at the mossy fiber-granule cell synapse in the adult mouse cerebellum. Eur. J. Neurosci. 13, 2025-2036.

Yuan, Q., Qiu, D.L., Weber,J.T., Hansel, C., and Knöpfel, T. (2007). Climbing fibertriggered metabotropic slow potentials enhance dendritic calcium transients and simple spike firing in cerebellar Purkinje cells. Mol. Cell. Neurosci. 35, 596-603.

Conflict of Interest Statement: The authors declare that the research was conducted in the absence of any commercial or financial relationships that could be construed as a potential conflict of interest.

Received: 11 March 2009; paper pending published: 31 March 2009; accepted: 09 June 2009; published online: 06 July 2009. Citation: Ohtsuki G, Piochon C and Hansel C (2009) Climbing fiber signaling and cerebellar gain control. Front. Cell. Neurosci. (2009) 3:4. doi:10.3389/neuro.03.004.2009

Copyright $\odot 2009$ Ohtsuki, Piochon and Hansel. This is an open-access article subject to an exclusive license agreement between the authors and the Frontiers Research Foundation, which permits unrestricted use, distribution, and reproduction in any medium, provided the original authors and source are credited. 